\title{
Modelagem da dinâmica de rebanho de bovino de corte por meio de cadeia de Markov
}

\author{
Urbano Gomes Pinto de Abreu ${ }^{I^{*}}$ Sandra Aparecida Santos ${ }^{\mathrm{I}}$ Paulo Sávio Lopes ${ }^{\mathrm{II}}$ \\ Robledo de Almeida Torres ${ }^{\text {II }}$ Heleno do Nascimento Santos ${ }^{I I}$
}

\section{- NOTA -}

\section{RESUMO}

A estrutura etária do rebanho e a estratégia de descarte de matrizes são pontos importantes na avaliação da eficiência do sistema de produção de gado de corte. Neste trabalho foi monitorado o rebanho de cria, cujas matrizes eram mantidas ou descartadas com base em critério técnico, conforme a avaliação do desempenho reprodutivo. Para tanto, foi utilizada a cadeia de Markov com o objetivo de simular a probabilidade de descarte por idade, ao longo da vida, e de calcular a expectativa de vida da matriz no rebanho. Após a introdução da estação de monta, a pressão de descarte foi maior, com aumento da probabilidade de descarte e da diminuição da probabilidade de permanência da matriz no rebanho nas idades mais avançadas. Com a introdução de tecnologias e especialmente da monta controlada, o processo torna-se mais dinâmico com a identificação e descarte de novilhas e matrizes improdutivas, diminuindo a idade média das vacas no rebanho e de descarte das mesmas.

Palavras-chave: análise de sistema de produção, descarte de matrizes, introdução de tecnologias.

\section{ABSTRACT}

The determination of age structure in a herd and the culling strategy in dams are important points to evaluate efficiency of a beef cattle production system. A breeding herd was monitored, where cows were maintained or discard according to technical criterion. Using the Markov chain the culling probability due to age throughout the life time of the cow was simulated. Life expectancy of the dam in the herd was also calculated. After the breeding season, culling pressure was higher and culling probability increased while permanency probability in the herd for older cows decreased, this made the herd more dynamic.
Key words: analysis of production system, dam culling, technology introduction.

A pecuária de corte no Pantanal é desenvolvida em criatórios naturais extensivos, com as características de manejo pautadas pelo regime de enchentes. Nesse sistema, os animais recebem poucos cuidados e são mantidos quase que exclusivamente em pastagens nativas das extensas planícies arenosas e com poucas subdivisões (invernadas), de forma a permitir o uso de aguadas e o pastejo seletivo. O manejo dos animais na propriedade resume-se aos "trabalhos de gado” (TGs) anuais, sendo que o primeiro é realizado em maio ou junho e o segundo é realizado em novembro ou dezembro.

Em sistemas extensivos de cria, com o número estabilizado de animais no rebanho, a comercialização de fêmeas excedentes (novilhas) e de fêmeas de descartes (vacas velhas) é de grande importância, pois corresponde a cerca de 50\% da receita bruta dos produtores de bezerros (ABREU et al., 2003). Assim, a determinação da estrutura etária do rebanho e da estratégia de descarte são pontos importantes na avaliação da eficiência econômica do sistema de produção como um todo. Em vista disso, o presente trabalho tem como objetivo avaliar os impactos de diferentes estratégias de descarte das matrizes, simulando a expectativa de vida útil e a idade média de

'Embrapa Pantanal, CP 109, 79320-900, Corumbá, MS, Brasil. E-mail: urbano@cpap.embrapa.br. *Autor para correspondência.

"Universidade Federal de Viçosa (UFV), Viçosa, MG, Brasil. 
descarte em rebanho comercial de cria, utilizando cadeia de Markov.

Para realização deste trabalho, no período de 1994 a 1999, foi efetuado acompanhamento no sistema de produção do rebanho de cria da fazenda Chatelodo, na sub-região da Nhecolândia, com introdução de tecnologias desenvolvidas pela Embrapa Pantanal. Utilizando-se metodologia de equações de estimação generalizadas (GEE), foram estimadas probabilidades de descarte das matrizes, para cada invernada da propriedade, ao longo do período de monitoramento que compreendeu um total de 11 TGs. As tecnologias desenvolvidas pela Embrapa Pantanal e implantadas na propriedade foram as seguintes: desmama antecipada, everminação estratégica das fêmeas de reposição, identificação das matrizes com acompanhamento reprodutivo das mesmas, descarte baseado em desempenho, monta controlada, utilização de touros oriundos de plantel de seleção da própria fazenda, avaliação andrológica dos touros e redução da proporção touro:vaca. Essas tecnologias foram implantadas em etapas ao longo do trabalho de monitoramento, conforme descrito por ABREU et al. (2006). O descarte das matrizes ocorreu em função de idade (mais de 14 anos) ou do desempenho reprodutivo deficiente. As fêmeas que foram classificadas como "solteiras" em dois TGs subseqüentes eram descartadas após a realização do diagnóstico de gestação.

Com o objetivo de dar suporte à modelagem de sistemas de produção e análise do desempenho das matrizes, GREER et al. (1980) propõem a estimativa de cinco probabilidades básicas por idade da matriz: a) probabilidade da vaca ser descartada em determinada idade, b) probabilidade de a vaca não ser descartada em determinada idade, $c$ ) probabilidade de a vaca aos dois anos de idade entrar no rebanho e permanecer até determinada idade, d) proporção das vacas no rebanho com determinada idade e e) expectativa de vida das matrizes no rebanho.

Neste trabalho, utilizou-se metodologia com base em cadeia de Markov descrita por AZZAM et al. (1990) com o objetivo de analisar o descarte de vacas em rebanho de cria. Essa metodologia permitiu estimar a distribuição de idades no rebanho quando o mesmo encontra-se em equilíbrio. A matriz de transição descreve a estratégia de descarte (a probabilidade que um animal possui em ser mantido em determinado ano ou de ser substituído por uma novilha). Os elementos $\left(p_{i j}\right)$ da matriz de transição $P$ representam a probabilidade que o animal de determinada idade ( $i$ ) em reprodução ser retido por mais um ano $(j=i+1)$ ou ser substituído por uma novilha de dois anos $(j=1)$. Em razão de que a matriz poder ser apenas um ano mais velha em cada ano subseqüente ou ser substituída por uma novilha, todos os outros elementos de $P$ são zero. A matriz de transição é utilizada para determinar a proporção de animais em cada idade quando o sistema é estabilizado, por meio da solução dos sistemas de equações. Sendo $\pi$ um vetor coluna que possui em seus elementos as proporções das idades das matrizes em equilíbrio (quando o sistema encontra-se estabilizado). Estas proporções são encontradas pela solução da série de equações simultâneas $\pi=P \pi$. Entretanto, por meio da resolução direta do sistema de equações, não é possível encontrar solução única. Assim, uma equação é arbitrariamente eliminada e substituída pela equação $\Sigma_{i} \pi_{i}=1$, que é a restrição que determina a adição de um a todas as proporções. Para a operacionalização do procedimento, foi desenvolvido um programa em Interactive Matrix Language (IML), do pacote estatístico SAS (2005), sendo utilizada a probabilidade de descarte da invernada intitulada de Baitaca para análise da metodologia.

Na figura 1, observamos as probabilidades A e B, estimadas para os 11 TGs realizados durante o monitoramento na invernada Baitaca. Observa-se que os TGs iniciais foram semelhantes ao sistema tradicional, ou seja, o descarte praticamente só aconteceu por idade, sem nenhum critério técnico.

Com a introdução de tecnologias, as probabilidades de descarte aumentaram e de permanência diminuíram na medida em que mais tecnologias eram implantadas, permitindo a realização de descarte técnico com mais eficiência. Logo após a implantação da estação de monta no TG7 foi significante o descarte realizado devido à identificação de fêmeas com desempenho inferior. No entanto, o produtor deve ter em conta que, ao aumentar o número de fêmeas descartadas, há necessidade de ter a disposição novilhas aptas para iniciar o ciclo reprodutivo. Se isso não acontecer, a reposição poderá ficar comprometida, com perdas a médio e longo prazo, causadas pela diminuição das fêmeas do rebanho de cria.

As idades médias de matrizes no rebanho foram 9,02 e 10,42 anos e de descarte foram 14,07 e 17,39 anos, respectivamente para o TG7 e o TG11. A idade é próximas à idade preconizada por ABREU et al. (1997) para matrizes no Pantanal, que recomendaram a idade de 14 anos para descarte por idade das vacas na região. Na figura 2 são apresentadas as probabilidades de descarte por idade durante os TGs. As probabilidades de descarte para as diferentes idades não dependem apenas da idade das matrizes. Em todas 


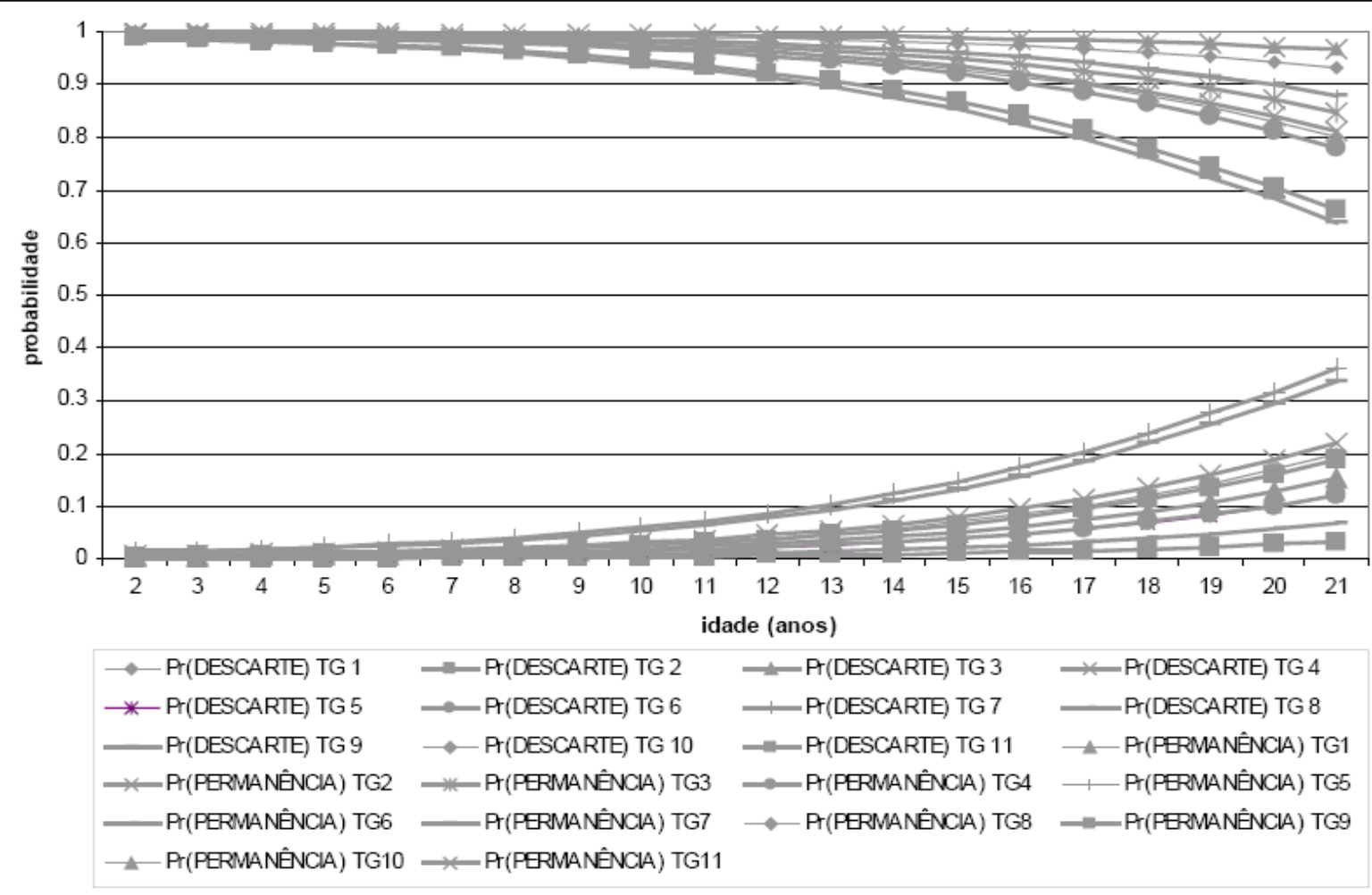

Pr - probabilidade; TG - trabalho de gado.

Figura 1 - Probabilidades de descarte e permanência na invernada Baitaca em função da idade da matriz.

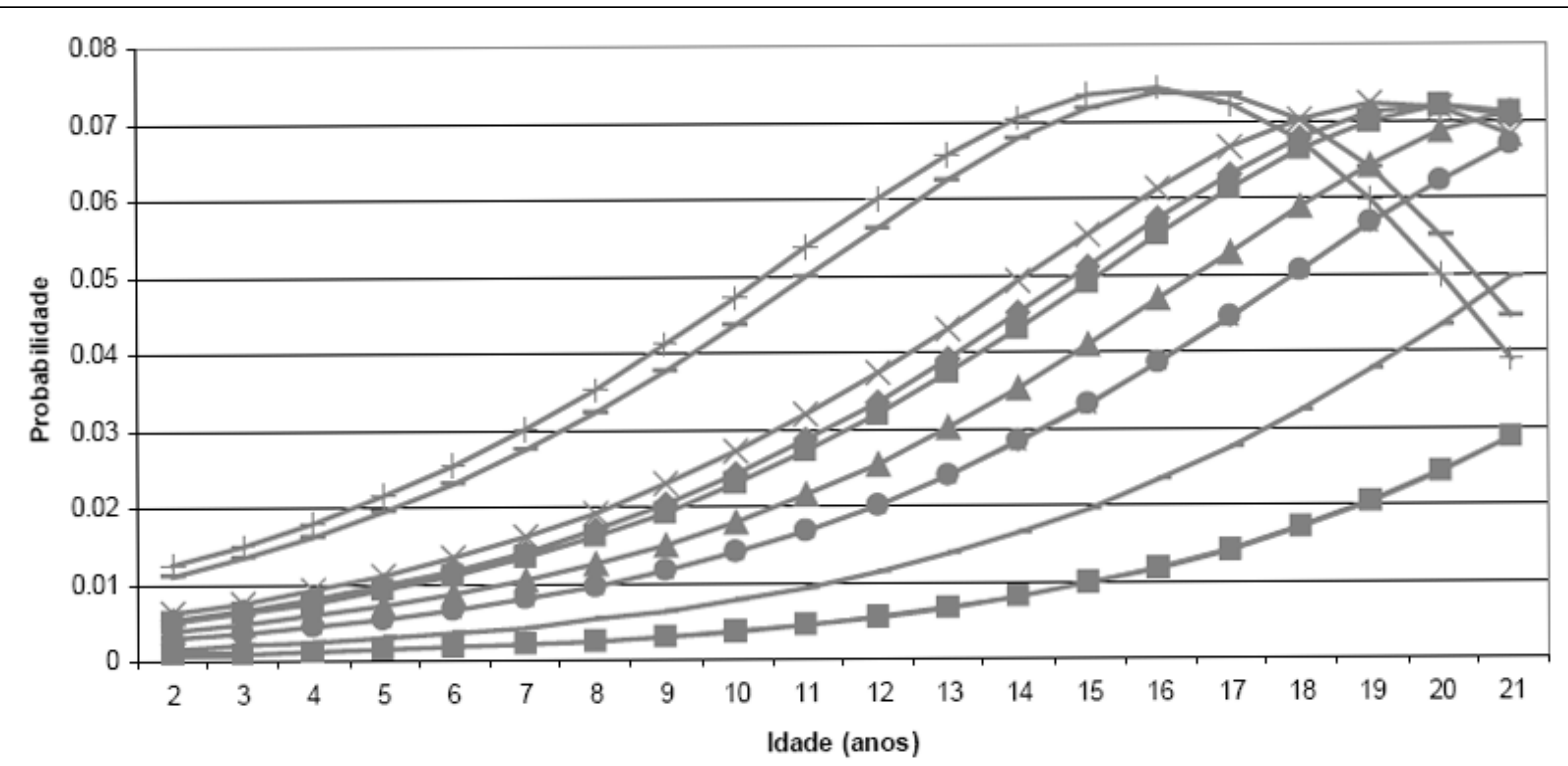

$$
\begin{aligned}
& \multimap \text { DESCARTEPORIDADE_TG1 --DESCARTEPOR IDADE_TG2 —DESCARTEPOR IDADE_TG3 } \\
& \text {-DESCARTEPORIDADE_TG4 } \rightarrow \text { DESCARTEPORIDADE_TG5 } \rightarrow \text { DESCARTEPOR IDADE_TG6 } \\
& \text { _DESCARTEPORIDADE_TG7 DESCARTEPOR IDADE_TG8 DDESCARTEPOR DADE_TG9 } \\
& \because \text { DESCARTEPOR IDADE_TG10 }=\text {-DESCARTEPOR IDADE_TG11 }
\end{aligned}
$$

Pr - probabilidade; TG - trabalho de gado.

Figura 2 - Probabilidade de descarte das matrizes em sistema de produção ao longo do monitoramento do rebanho.

Ciência Rural, v.38, n.9, dez, 2008. 
as invernadas, as probabilidades de descarte apresentam tendências curvilíneas de descarte, demonstrando que a maior pressão de descarte ocorre em idades intermediárias como efeito das tecnologias implantadas, especialmente da estação de monta, levando à identificação das matrizes improdutivas em idades intermediárias, com conseqüente descarte (FONSECA, 1982). A análise da vida produtiva das matrizes do rebanho de cria permite o entendimento das conseqüências da tomada de decisão em relação à introdução de tecnologias em diferentes estágios de vida das mesmas e, conseqüentemente, do desempenho produtivo do rebanho como um todo. O descarte de vacas e novilhas é aspecto importante para a eficiência econômica da atividade de cria.

A introdução de tecnologias modifica fortemente a estratégia de descarte de matrizes no sistema de produção extensivo do Pantanal. A utilização da metodologia de cadeia de Markov possibilitou modelar as diferentes situações observadas ao longo do processo.

\section{AGRADECIMENTO}

Ao Centro de Pesquisa do Pantanal (CPP), pelo apoio ao trabalho de monitoramento de fazendas.

\section{REFERÊNCIAS}

ABREU, U.G.P. et al. Avaliação da introdução de tecnologias no sistema de produção de gado de corte no Pantanal. Desempenho e descarte de matrizes. Revista Brasileira de Zootecnia, v.35, n.6, p.2496-2503, 2006.

ABREU, U.G.P. et al. Análise bioeconômica da introdução de período de monta no sistema de produção de rebanhos de cria na região do Brasil central. Revista Brasileira de Zootecnia, v.32, p.1198-1206, 2003

ABREU, U.G.P. et al. Desempenho produtivo de vacas aneloradas no Pantanal - sub-região da Nhecolândia. In: REUNIÃO ANUAL DA SOCIEDADE BRASILEIRA DE ZOOTECNIA, 34., 1997, Juiz de Fora, MG. Anais... Juiz de Fora: Sociedade Brasileira de Zootecnia, 1997. 377p. p.292294

AZZAM, S.M. et al. Markov chains as shortcut method to estimate age distributions in herds of beef cattle under different culling strategies. Journal of Animal Science, v.68, p.5-14, 1990.

FONSECA, V.O. da. Reprodução em bovinos (fatores que influenciam a eficiência reprodutiva). Informe Agropecuário, n.89, p.70-80, 1982.

GREER, R.C. et al. Estimation of probability of beef cows being culled and calculation of expected herd life. Journal of Animal Science, v.51, p.10-19, 1980.

STATISTICAL ANALYSIS SYSTEM - SAS. User's guide. versão 9.1.ed. Cary: SAS Institute, 2005. (CD-ROM). 